Año LXXXII. urtea $279-2021$

Enero-abril Urtarrila-apirila

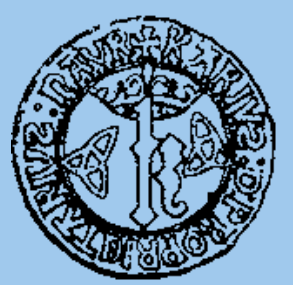

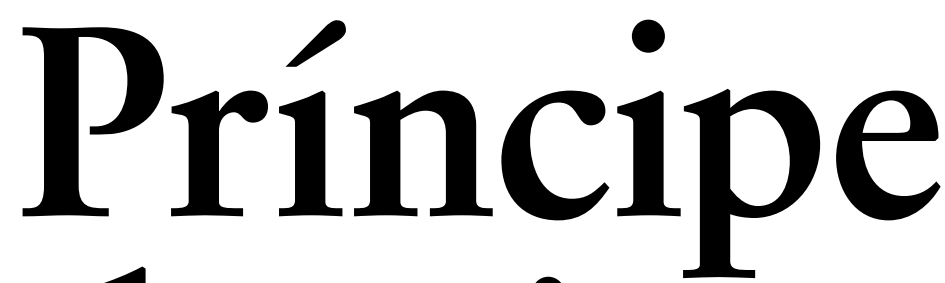
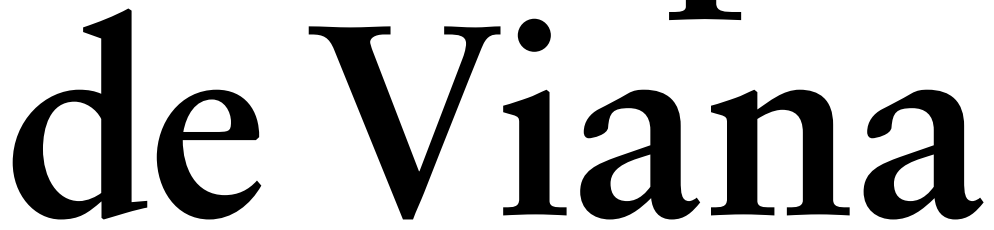

SEPARATA

Un formulario de la

Secretaría de Aragón del Consejo de la Inquisición (BC, ms. 2168)

Anna GUDAYOL 


\section{Sumario / Aurkibidea}

\section{Príncipe de Viana}

Año LXXXII • n. ${ }^{\circ} 279$ - enero-abril de 2021

LXXXII. urtea $\cdot 279$. zk. 2021 ko urtarrila-apirila

\section{GUSTAV HENNINGSEN / MARISA REY-HENNINGSEN}

\section{Homenaje / Omenaldia}

Ignacio Panizo (coord./koord.)

Vol. II. lib.

\section{ESTUDIOS DE INVESTIGACIÓN EN HOMENAJE \\ A GUSTAV HENNINGSEN Y MARISA REY-HENNINGSEN / \\ IKERKETA LANAK, GUSTAV HENNINGSENEN \\ ETA MARISA REY-HENNINGSENEN OMENEZKOAK}

Entre impostores anda el juego en el Siglo de Oro. Dos vizcaínos ante la Inquisición y unos conversos toledanos próximos a Garibay

Un formulario de la Secretaría de Aragón del Consejo de la Inquisición (BC, ms. 2168)

Anna Gudayol

Las cartillas editadas en Estella e incautadas en Medellín por la Inquisición (1561)

Javier Itúrbide Díaz

El Tribunal de Navarra y sus funcionarios inquisitoriales:

algunas observaciones

Consuelo Juanto Jiménez

Goya investigado por la Inquisición: la censura de los Caprichos en 1804

$\mathrm{El}$ «Informe del inquisidor Avellaneda» sobre las complicidades brujeriles en los valles centrales y orientales del Pirineo navarro José M. Floristán Imízcoz, Jesús Moya Mangas 


\section{Sumario / Aurkibidea}

La Inquisición en Tudela durante los siglos XVI y XVII:

presencia e incidencia social

Iñigo Pérez Ochoa

La huella de la Inquisición en la Biblioteca de Navarra

Roberto San Martín Casi

Los memoriales como fuente para el estudio de la Inquisición

en el Tribunal de Navarra (1609-1621)

Bárbara Santiago Medina

De comisarios, confesores y vecinos: la proyección de la Inquisición

a finales del Antiguo Régimen

Marina Torres Arce

Los niños como víctimas y los niños como verdugos en la caza de brujas:

Navarra, siglo XVI

Jesús M. Usunáriz

Volver a las relaciones de causas. El ejemplo de los berberiscos

del reino de Granada

Bernard Vincent

\section{LOS TRABAJOS Y LOS DÍAS DEL AÑO 2020 / 2020ko LANAK ETA EGUNAK}

Tesis doctorales sobre temática navarra de ciencias humanas, sociales y jurídicas, leídas en 2020

(Según la Base de datos Teseo del Ministerio de Educación)

Narrativa de autores navarros en castellano, año 2020

Mikel Zuza Viniegra

Euskarazko literaturak 2020an zer?

Ángel Erro Jiménez

Donación del fondo bibliográfico y documental Gustav Henningsen y Marisa

Rey a la Universidad Pública de Navarra

Iñaki Montoya Ortigosa

Formación en Archivística y Gestión Documental en la Universidad de Navarra

Yolanda Cagigas Ocejo

6 Príncipe de Viana (PV), 279, urtarrila-apirila, 2021

ISSN: 0032-8472 | ISSN-e: 2530-5824 | ISSN-L: 0032-8472

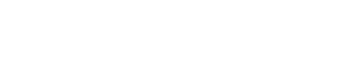




\section{Sumario / Aurkibidea}

Apuntes sobre etnografía, folclore y cultura tradicional David Mariezkurrena Iturmendi

El alivio y reparo. La forma audiovisual

Marga Gutiérrez Díez

Proceso de decantación. Exponer en 2020

Mireya Martín Larumbe

Exposición «Maleficium. Navarra y la caza de brujas. Siglos XIV-XVII»

(Archivo Real y General de Navarra, julio-diciembre, 2020)

Jesús M. Usunáriz

Carlos Cánovas

Alicia Ezker Calvo

Discurso Premio Príncipe de Viana 2020

Carlos Cánovas Ciaurriz

Currículums

Analytic Summary

Normas para la presentación de originales / Idazlanak aurkezteko arauak /

Rules for the submission of originals 


\title{
Un formulario de la Secretaría de Aragón del Consejo de la Inquisición (BC, ms. 2168)
}

Inkisizioaren Kontseiluaren Aragoiko Idazkaritzaren formulario bat (BC, 2168. eskuizkribua)

A formulary of the Aragon Secretariat of the Inquisition Council (BC, ms. 2168)

\author{
Anna Gudayol \\ Biblioteca de Catalunya \\ agudayol@bnc.cat \\ https://orcid.org/0000-0002-6671-5266 \\ DOI: https://doi.org/10.35462/pv.279.2
}

Agradecimientos: Ignacio Panizo.

Recepción del original: 13/01/2021. Aceptación provisional: 10/03/2021. Aceptación definitiva: 27/04/2021. 


\section{RESUMEN}

Descripción de un formulario inquisitorial que contiene alrededor de ciento veinte modelos de documentos, compilado en la Secretaría de Aragón del Consejo de la Inquisición y conservado actualmente en la Biblioteca de Catalunya, y edición del sumario, para darlo a conocer y facilitar su estudio.

Palabras clave: Inquisición; formularios; funcionarios inquisitoriales; Biblioteca de Catalunya.

\section{LABURPENA}

Inkisizio-formulario bat deskribatzen da, ehun eta hogei dokumentu-eredu inguru dituen bat, Inkisizioaren Kontseiluko Aragoiko Idazkaritzan bildua eta egun Kataluniako Liburutegian gordetzen dena. Sumarioaren edizioa ematen da, ezagutarazteko eta errazago aztertu ahal dadin.

Gako hitzak: Inkisizioa; formularioak; Inkisizioaren funtzionarioak; Kataluniako Liburutegia.

\section{ABSTRACT}

Description of an Inquisition formulary, containing around one hundred and twenty forms of different documents, compiled at the Aragon's Inquisition Council, held nowadays at the Library of Catalonia (Biblioteca de Catalunya), and edition of its table of contents, in order to make it known and facilitate its study.

Keywords: Inquisition; formularies; Inquisition officials; Library of Catalonia (Biblioteca de Catalunya). 
1. INTRODUCCIÓN. 2. DOCUMENTACIÓN INQUISITORIAL EN LA BIBLIOTECA DE CATALUNYA. 3. FORMULARIO DE TODO GÉNERO DE DESPACHOS ASÍ PÚBLICOS COMO DE FEE Y OTROS IRREGULARES (BC, ms. 2168). 3.1. La colección teatral de don Arturo Sedó. 3.2. Descripción física. 3.3. Identificación. 4. SUMARIO DEL FORMULARIO DE TODO GÉNERO DE DESPACHOS ASÍ PÚBLICOS COMO DE FEE Y OTROS IRREGULARES. 5. LISTA DE REFERENCIAS.

\section{INTRODUCCIÓN}

Uno de los retos a los que se enfrentan los investigadores en cualquier disciplina es el de llegar a identificar con precisión dónde se encuentra la documentación necesaria para hacer avanzar sus pesquisas. En el caso de los historiadores de la Inquisición la tarea puede parecer relativamente sencilla: vista la importancia de su tarea, la institución se ocupó relativamente pronto de conservar y ordenar sus papeles, que forman la base del fondo conservado en la Sección de la Inquisición del Archivo Histórico Nacional. Otros archivos de la red de archivos estatales (Corona de Aragón, Simancas, Indias, Real Chancillería, Nobleza), así como la Biblioteca Nacional, conservan documentación inquisitorial manuscrita, aunque sea en una medida mucho menor.

Sin embargo, merece la pena recordar que la historia de los archivos es con frecuencia azarosa, y que por ello algunas piezas útiles para el estudio de la Inquisición pueden encontrarse en lugares insospechados. Sería el caso, por ejemplo, de un curioso formulario inquisitorial -una compilación de fórmulas y modelos usados por los miembros del tribunal del Santo Oficio para redactar peticiones, ejecuciones, nombramientos y otros documentos-, conservado en la Biblioteca de Catalunya, en donde ingresó como parte de una colección teatral, en la que nadie en su sano juicio habría buscado un volumen de estas características. El objeto de este breve trabajo es presentar dicho volumen, a fin de ponerlo a disposición de los estudiosos. 


\section{DOCUMENTACIÓN INQUISITORIAL EN LA BIBLIOTECA DE CATALUNYA $^{1}$}

La Biblioteca de Catalunya fue fundada en 1907 como biblioteca del Institut d'Estudis Catalans, con la misión de recopilar fuentes relacionadas con la historia, lengua y literatura catalanas que pudieran servir de base a los académicos para sus trabajos, y de adquirir la bibliografía científica que facilitara su análisis y estudio. La buena acogida de la institución por la sociedad catalana hizo que pronto fuera objeto de numerosos donativos, que unidos a la excelente gestión de su joven director, Jordi Rubió y Balaguer, la convirtieron en un punto de referencia para los estudiosos. Durante la Guerra Civil llevó a cabo la salvaguarda del patrimonio bibliográfico catalán; durante la postguerra, bajo la tutela de la Diputación, continuó ejerciendo la función de biblioteca patrimonial, que ha perdurado hasta nuestros días.

El objetivo primero de la institución, unido a su fecha de creación y a las características de la constitución de sus fondos (mayoritariamente colecciones y donativos de particulares, junto a compras puntuales) hacen que la documentación inquisitorial en la Biblioteca de Catalunya sea poca y muy dispersa. Aun así, no está exenta de interés, ya que los materiales que conserva son, en general, poco conocidos. Podríamos mencionar entre ellos:

- Un breve conjunto de cartas e instrucciones relativas a la Inquisición en el virreinato del Perú durante el gobierno de Manuel de Amat y de Junyent (1761-1776), de fray Julián de Arriaga y Rivera y el inquisidor general Manuel Quintano Bonifaz.

- Las actas de distinto tipo (ventas, donativos, testamentos inventarios...) conservadas en la colección de pergaminos, sobre todo entre los pertenecientes al archivo del marquesado de Moja y al del Hospital de la Santa Cruz (muchos de ellos obra de Guillem Llaurador, notario real y escribano de secuestros de la Inquisición).

- Los edictos, cédulas, instrucciones, procesos y otra documentación relativa a la Inquisición integrados en la colección de Folletos Bonsoms (formada por impresos breves y pliegos de cordel).

- La correspondencia de distintos inquisidores de finales del siglo XVIII y principios del XIX (Felipe Bertrán Serrano, Agustín Rubín de Ceballos, Manuel Abad y Lasierra, Francisco Antonio de Lorenzana, José Poveda (OP), Ramón José de Arce) conservada en el archivo familiar de Félix Torres Amat, que incluye igualmente la documentación de su tío, el obispo ilustrado Félix Amat.

- Un conjunto de piezas probatorias extraídas de los procesos de la Inquisición en Cerdeña, fruto de la expedición del diplomático Eduardo Toda para buscar materiales sobre las Cortes españolas, ingresado con la biblioteca italiana del coleccionista.

- Algunos documentos sueltos procedentes de compras a librerías anticuarias de la época (Salvador Babra, Josep Porter).

1 Agradezco a Ignacio Panizo la oportunidad que me brindó de presentar brevemente estos materiales en el III Simposio Internacional de Estudios Inquisitoriales celebrado en la Universidad de Alcalá de Henares entre el 10-12 de junio de 2015, así como su disponibilidad para hacer verificaciones en los fondos del Archivo Histórico Nacional, que conoce mejor que nadie. 
Ahora bien, posiblemente la pieza más destacada sea, como se apuntaba al inicio, un formulario inquisitorial ingresado a través de la compra de una colección literaria compilada por Arturo Sedó.

\section{FORMULARIO DE TODO GÉNERO DE DESPACHOS ASÍ PÚBLICOS COMO DE FEE Y OTROS IRREGULARES (BC, ms. 2168)}

\subsection{La colección teatral de don Arturo Sedó}

El ingeniero barcelonés Arturo Sedó y Guichard (1881-1965) pertenecía a una familia de industriales que dirigía una próspera colonia textil no muy lejos de Barcelona, las «Manufacturas Sedó». Hombre culto y apasionado por la música y la literatura, Sedó constituyó, a lo largo de su vida, una extraordinaria biblioteca estimada en alrededor de noventa mil volúmenes, instalada en su mansión en el céntrico ensanche barcelonés. La colección era conocida como «Colección teatral de don Arturo Sedó» por su especialización en el teatro, pero entre las decenas de miles de volúmenes incluía muchos otros materiales: partituras (Sedó era un buen pianista), álbumes románticos, manuscritos poéticos del Siglo de Oro (entre los cuales, un volumen con anotaciones autógrafas de Góngora), textos de la Ilustración, obras religiosas, mapas y grabados, libros de bibliófilo y un sinfín de documentos menores. Una parte significativa provenía de distintas colecciones de eruditos, como las de Aureliano Fernández-Guerra (1816-1894), Emilio Cotarelo (1857-1936) o Joaquín Montaner (1892-1957), que tras la compra de su biblioteca realizó el catálogo de las piezas más destacadas de la colección teatral (Montaner, 1951). La biblioteca incluía volúmenes que habían pertenecido a algunos bibliófilos eminentes, como el marqués de Pidal, Georges Ticknor o Ricardo de Heredia. Se trataba, probablemente, de la biblioteca privada más importante de la Barcelona de la postguerra; a pesar de ser conocida esencialmente como colección teatral, la amplitud real de la colección y la diversidad de su contenido justifican que pudiera hallarse en ella un volumen relativamente excéntrico como el formulario inquisitorial que nos ocupa.

A su muerte, la familia decidió vender la valiosa colección. Guillermo Díaz-Plaja, director del Instituto del Teatro, propuso la compra de la biblioteca a la Diputación de Barcelona; para justificar su interés, si cupiera, se basó en un informe entusiástico de Antonio Rodríguez-Moñino ${ }^{2}$. La Diputación distribuyó los materiales que la conformaban entre dos instituciones que, en aquel entonces, dependían de ella, la Biblioteca Central de la Diputación (nombre otorgado por las autoridades franquistas a la Biblioteca de Catalunya) y el Instituto del Teatro. La mayoría de los impresos, manuscritos y documentación teatral, que incluía papeles de los empresarios Luis Paris (Teatro Real de Madrid) o Josep Canals (Teatros Novedades, Romea y Tívoli), y fondos editoriales como el madrileño de la casa García Rico o el archivo teatral Lluís Milà, fueron desti-

2 Sobre los pormenores administrativos de la adquisición, véase Biblioteca de Catalunya, Archivo administrativo, c. 1170/4. 
nados a la biblioteca del Instituto del Teatro ${ }^{3}$, mientras que los volúmenes no teatrales y otro tipo de materiales (manuscritos, partituras y documentación musical, ediciones de bibliófilo y algunos libros de bibliófilo) se incorporaron a la Biblioteca de Catalunya ${ }^{4}$. Al llegar a la institución, los volúmenes y documentos se repartieron entre distintos departamentos según su tipología: los manuscritos al departamento de Manuscritos, las partituras al de Música, los mapas y libros ilustrados a la Reserva de Grabados, los libros de bibliófilo y raros a la Reserva Impresa, y los libros modernos al fondo general.

\subsection{Descripción física}

El formulario inquisitorial es un grueso volumen in folio en papel claro y de buena calidad, que mide $340 \times 240 \mathrm{~mm}$ y aproximadamente $50 \mathrm{~mm}$ de grueso; contiene 254 hojas numeradas en lápiz durante los años 80 por un funcionario de la biblioteca, Salvador Pastor. Tras dos hojas de guarda con sendos títulos (que detallaremos más adelante), de mano distinta a la de la copia, el volumen principia con un sumario de diez hojas (actuales ff. 1-10) que remite a la foliación original del libro; esta se inicia a continuación del sumario, a partir de la transcripción del primer documento, y ocupa 244 folios. Entre los folios 222 y 223 hay tres hojas mútilas; al final se aprecian igualmente los talones de catorce hojas cortadas. La copia de los documentos es relativamente uniforme, aunque la diferencia en el tintado de algunos finales de línea podría en algún caso hacer pensar en dos manos.

El volumen, encuadernado probablemente en origen a mediados del XVII o como muy tarde a principios del XVIII en piel marrón oscuro, lleva la cubierta estampada con hierros fríos. Ambos planos tienen la misma decoración: un rectángulo marcado con tres filas de doble hilo que crean dos corredores, el externo vacío y el interno ocupado por una cenefa con hierrecillos. El espacio interior del rectángulo está ocupado por un hierro central, flanqueado en la parte superior e inferior por otros dos hierros, más pequeños (el dibujo, muy gastado, no se reconoce, aunque podría tratarse de ángeles), y los ángulos internos están ornados con pequeños florones. El volumen conserva restos de unas bandeletas de cuero que servían para cerrar el volumen. Los cortes están pintados de rojo, y en el lomo hay inscrito en letras doradas el título «Framulari».

Aun cuando el estado de conservación del cuerpo y del papel es bueno, la encuadernación acusa un uso continuo: el cuero de las tapas está gastado, y la parte superior e inferior del lomo, por las cuales normalmente se atrapa el volumen, perdieron en su momento una parte del cuero que las recubría. Ambos extremos sufrieron una restauración antigua, probablemente durante el siglo XVIII, por la que se añadió a ambos extremos del lomo una tira de cuero oscuro; actualmente es poco perceptible porque con el paso del tiempo el color de la piel se ha oscurecido. Aun así, el lomo y el tajo están algo deformados. Los ángulos de la cubierta se hayan también muy gastados, con pérdida de

3 Al ingresar en la Diputación Dolores Givanel, bibliotecaria de la colección, dejó constancia del contenido y formación del fondo en la revista cultural de dicha institución (Givanel, 1969).

4 Del conjunto de dicha colección existían unos ficheros manuales, que actualmente se encuentran conservados en el Centre de Documentació-Museu de les Arts Escèniques de l'Institut del Teatre (MAE). 
material. Finalmente, en las tapas y en la parte que toca al lomo se aprecian algunas ligeras galerías de parásitos, a quienes parece haber interesado más el engrudo de la cola de la encuadernación que el bello y blanco papel del cuerpo del libro.

El volumen había pasado por la librería de Josep Porter, el librero anticuario más importante de la postguerra. Nos lo indica el hecho que en la hoja de guarda, tras el título del volumen, haya inscrita en lápiz con la escritura ancha y deslavazada del anticuario la anotación "Inquisición / 79», y que en el ángulo superior externo del f. 254v hallemos la expresión numérica «11100/750», característica de los libros que pasaron por su establecimiento. La nota «Inquisición / 79» parece dar a entender que el volumen formaba parte de un conjunto de documentación inquisitorial, elaborado tal vez con la intención de venderlo en bloque (algo no raro en el librero) pero que finalmente se vendió de manera individual, pieza a pieza; teniendo en cuenta que antes de la guerra las notas de Porter acostumbran a estar escritas en catalán, lo más probable es que el libro fuera incorporado al lote, y por lo tanto vendido, después de la Guerra Civil.

Actualmente el manuscrito lleva las marcas de posesión de la Colección Sedós: el exlibris, que representa un telón que se abre sobre un conjunto de libros y que deja ver al fondo un escenario teatral, pegado en el ángulo superior izquierdo del contraplano anterior, y el número de registro, «68595», escrito en una pequeña etiqueta de papel enmarcada por una cenefa dorada y fijado en el ángulo superior derecho de la primera hoja de guarda. En cambio, no se especifica, como en algunos otros libros de la colección, la signatura topográfica que indicaba el armario y estante en el que se conservaba en la biblioteca Sedó. Al ingresar en la Biblioteca de Catalunya se le atribuyó el número de registro de manuscritos ms. 2168, por el que se recupera y es conocido actualmente.

\subsection{Identificación}

El formulario va identificado en las dos hojas de guarda por dos títulos similares, pero no idénticos. En la primera hoja de guarda una mano de la primera mitad del siglo XVII, prácticamente coetánea al texto, anotó lo siguiente:

Formulario de todo género de despachos así públicos como de fee y otros irregulares.

Hay también razón de lo que se executa en posesión del sr. Inquisidor general y del modo con que se hacen los títulos de secretarios y ministros del Consejo y lo que sucede en otros casos que expresa la tabla.

El examen de los distintos documentos transcritos en el formulario nos permite apreciar que la mayoría de las fórmulas tomadas como ejemplo fueron escritas durante las décadas de 1610-1620; por lo tanto, podríamos suponer que el título de dicha hoja habría sido trazado probablemente alrededor de 1625-1630.

5 No aparece listado en el catálogo de Montaner (1951); pero se trata de un catálogo selectivo de piezas de teatro, en el que no figuran tampoco, por ejemplo, los álbumes o las ejecutorías. 


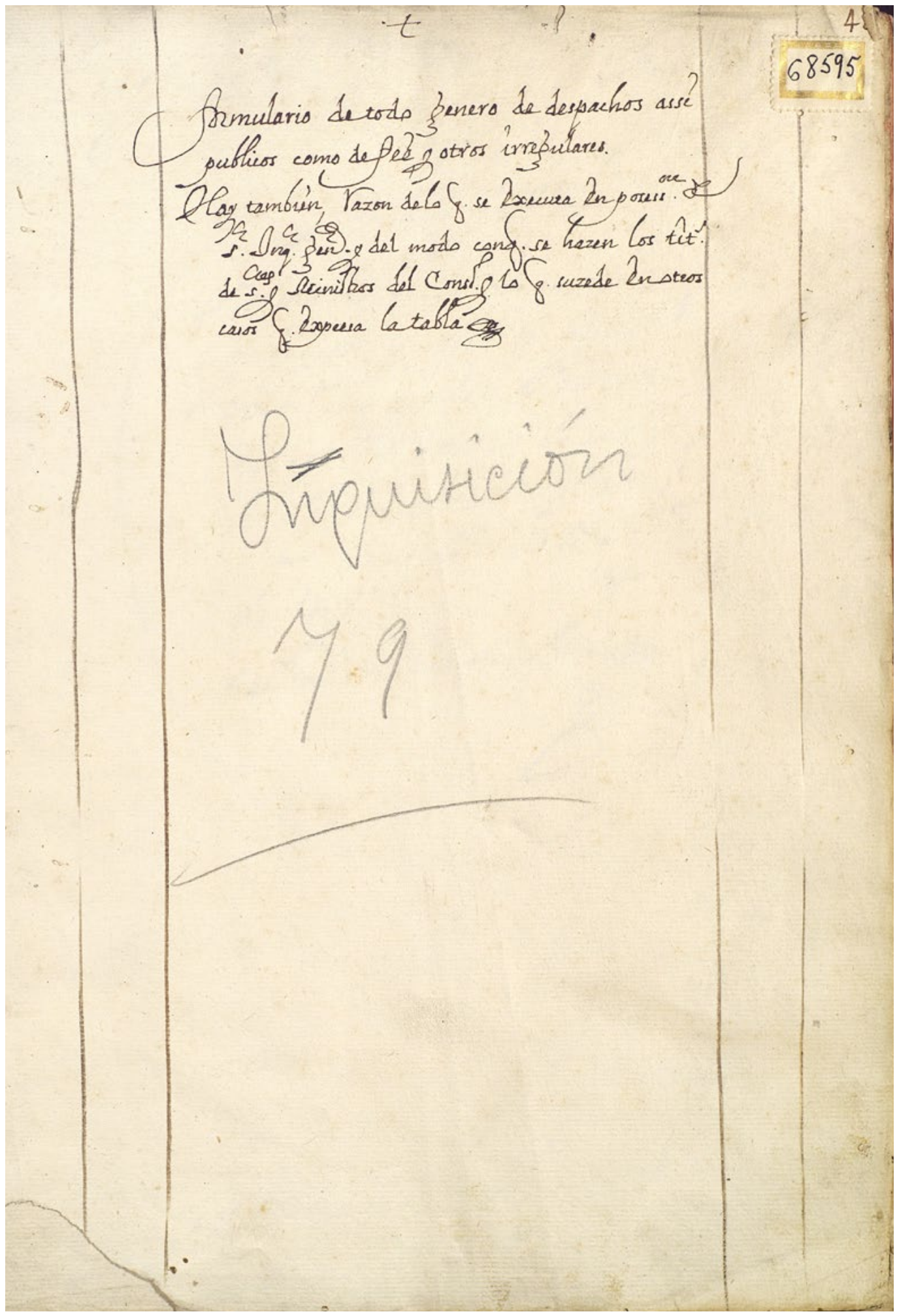

Figura 1. BC, ms. 2168, primera hoja de guarda. Inscripción del siglo XVII. 


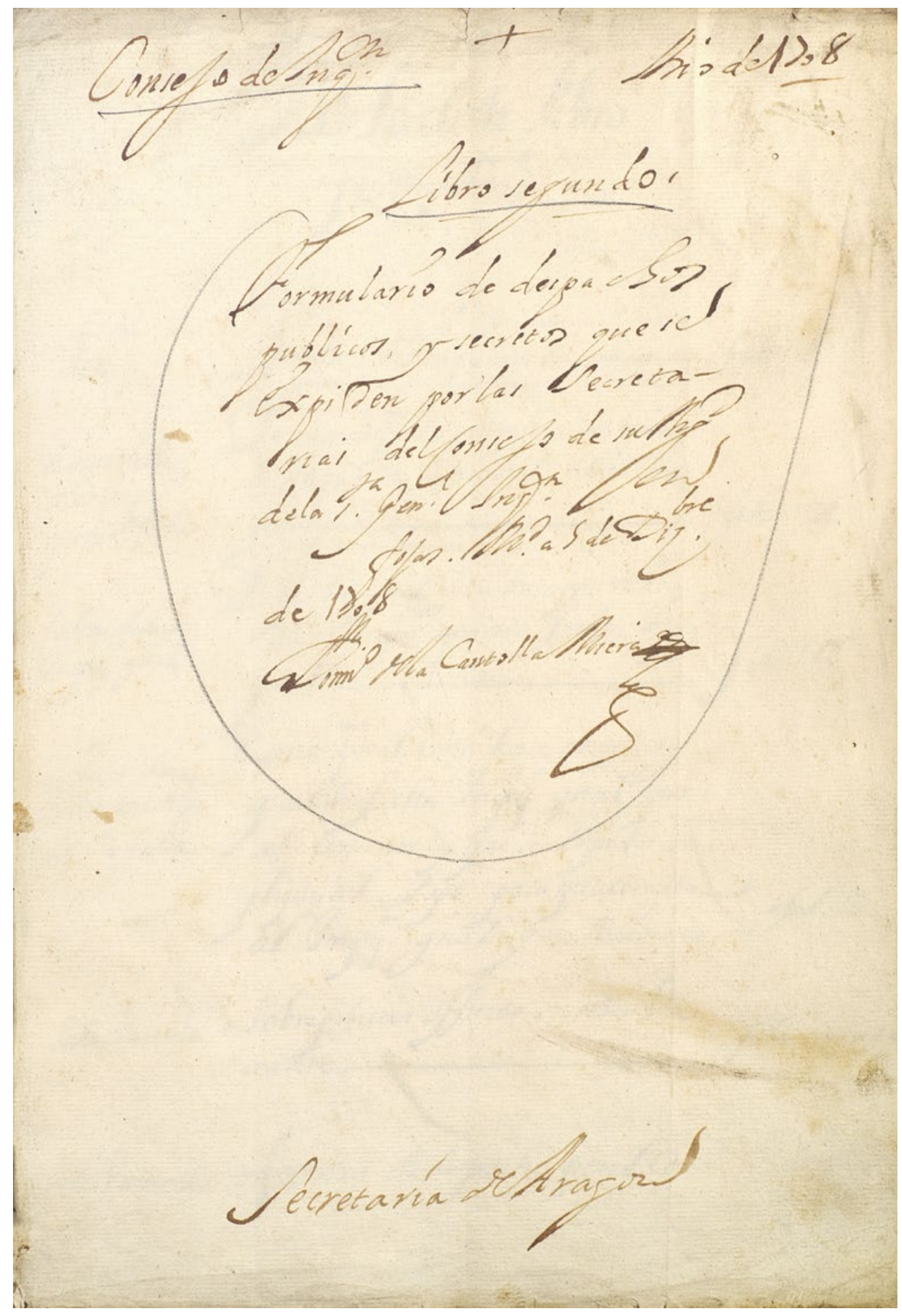

Figura 2. BC, ms, 2168, segunda hoja de guarda. Inscripción de Domingo de la Cantolla Miera, 1708. 
Posteriormente, a principios del siglo XVIII, se añadió en la segunda hoja de guarda un nuevo título, bastante similar pero no idéntico; la inscripción va firmada por el secretario Domingo de la Cantolla Miera y Heras, y fechada en 1708.

\section{Consejo de Inquisición Año de 1708}

Libro segundo / Formulario de despachos públicos y secretos que se expiden por las secretarías del Consejo de su Magestad de la Santa General Inquisición en [...] hojas. Madrid, a 5 de diciembre de 1708

Domingo de la Cantolla-Miera Secretaría de Aragón.

Esta nota se refiere, muy claramente, a la reordenación de los fondos de archivo efectuada por el secretario Domingo de la Cantolla Miera a principios del siglo XVIII (Pérez, 2015, pp. 55-65), que ha sido objeto tanto de alabanzas como de críticas, pero que muy probablemente tiene la virtud de haber permitido gran parte de la conservación de los archivos inquisitoriales. La mención «Libro segundo»-indicación que no aparece en el título proporcionado en su origen- sugiere que en el momento de la reestructuración del archivo el volumen se ordenó a continuación de un volumen de contenido similar, pero probablemente algo anterior.

Hace algunos años, en un estudio particularmente útil para seguir la historia de los fondos de la Sección Inquisición del Archivo histórico Nacional (Avilés, Martínez \& Pinto, 1978) se editaron en apéndice diversos inventarios antiguos de la documentación de archivo. La confrontación con dichos inventarios permite establecer que el título copiado en la primera hoja de guarda, la más antigua, aparece inscrito de forma idéntica en un asiento de un inventario del archivo de la secretaría de Aragón, establecido según sus editores después de la reestructuración de los libros efectuada por Domingo de la Cantolla. Lleva el número de ítem 221, y está incluido en una serie de «Varios»:

220. Otro intitulado Libro 1. Formulario antiguo de despachos. Recopilación.

221. Un libro intitulado Formulario de todo género de despachos, así públicos como de fe y otros irregulares.

(Avilés, Martínez \& Pinto, 1978, p. 507).

En el momento de la elaboración del artículo (1978), la mayoría de los volúmenes de los distintos asientos de los inventarios mencionados iban acompañados de la identificación con una signatura precisa del fondo de Inquisición del Archivo Histórico Nacional. No así estos dos volúmenes, que en dicho momento no habían sido identificados. Ahora bien, la identidad absoluta entre el título de la primera hoja de guarda del ms. 2168 y el asiento del manuscrito creo que demuestran, sin lugar a dudas, que se trata del mismo volumen. Lo que es más difícil es saber en qué momento el libro se separó del fondo original. Arriesgaríamos dos hipótesis: podría ser que un inquisidor se lo llevara a casa para usarlo, como era relativamente común en ese momento, y no lo devolviera; a su muerte, la familia lo habría vendido con el resto de su biblioteca, pasando así al mercado público. Otra posibilidad sería que se hubiera perdido en algún momento en el siglo XIX, en el movimiento de fondos que tuvo lugar en el momento de 
la supresión del Tribunal del Santo Oficio. En cualquier caso, todo parece indicar que el volumen llevaba ya algún tiempo fuera de su archivo original en el momento en que ingresó en el fondo comercial de Porter.

Por otra parte, Martínez Millán, en un artículo sobre la Inquisición en tiempos de Carlos II, menciona la descripción de un volumen de la Sección Inquisición del Archivo Histórico Nacional (AHN, Inquisición, lib. 1283) con un título muy similar, aunque no idéntico, al que aparece en la segunda hoja de guarda, escrita en el momento de la reestructuración de Domingo de la Cantolla.

Formulario de despachos públicos y secretos que se expiden por la secretaria de Aragón del Consejo de Inquisición, 1708, realizado por Domingo de la Cantolla, en el que se hace especial relevancia a los nombramientos de oficios (Martínez Millán, 2017, p. 21, nota 42).

Según indica, en el formulario se incide particularmente en los nombramientos de oficios; y de hecho, los nombramientos son justamente el tipo de fórmulas más presente en el formulario que nos ocupa. Otra autora, Susana Cabezas, se refiere con la misma signatura (AHN, Inquisición, 1. 1283) a un cuaderno-formulario de la Inquisición elaborado a mediados del siglo XVI por un secretario del Consejo, Martínez de Lassao (Cabezas, 2002, p. 725, nota 31, 2005, p. 223).

Teniendo en cuenta las características de contenido y que cronológicamente parece anterior, creo que no es arriesgado proponer la identificación del volumen AHN, Inquisición, libro 1283 con el asiento 220 del inventario del archivo de la secretaría de Aragón publicado anteriormente (Avilés, Martínez \& Pinto, 1978, p. 507). Tendríamos así identificados los dos formularios descritos. Añadamos aquí la referencia a este formulario en el antiguo inventario de la documentación inquisitorial cuando estaba en Simancas y se remitió al Archivo Histórico Nacional. En el castillo simanquino, el libro de Inquisición tenía la signatura 992 y su descripción era la siguiente: «Libro $1 .^{\circ}$ formulario de despachos públicos y secretos que se espiden por la Secretaría de Aragón».

Al ingresar estos fondos en el Archivo Histórico Nacional, se le asignó una nueva signatura, que es la de libro 1283, como consta al margen de este inventario simanquino (f. 46r). Interesa además reseñar que nuevamente se hace referencia a un primer formulario, por lo que se desprende que había un segundo, que es indudablemente el manuscrito BC ms. 2168.

\section{SUMARIO DEL FORMULARIO DE TODO GÉNERO DE DESPACHOS ASÍ PÚBLICOS COMO DE FEE Y OTROS IRREGULARES}

El sumario, que como hemos indicado ocupa las diez primeras hojas, está dispuesto en tres columnas: la central y principal para las rúbricas de los documentos, flanqueada a la derecha por el número de folio y a la izquierda, en las primeras cuatro hojas, por una palabra o expresión que resume el contenido de dicha rúbrica. 
Su examen nos permite saber cuáles eran los ejemplos de documentos que los inquisidores consideraban necesarios. Al hojear la tabla del formulario vemos que contiene un gran número de fórmulas de nominación para los distintos cargos, tanto aquellos de más envergadura como los secundarios o los más técnicos (inquisidor e inquisidor general, fiscal, secretarios de la Corona de Castilla y de la Corona de Aragón, relator, receptor, alguacil y nuncio tanto del Consejo como de la Inquisición, portero, médico, cirujano, alcaide, tasador del Consejo, calificador del Consejo, notario del juzgado y notario de secretos, abogado del fisco, juez de bienes), así como listas de los salarios, fórmulas para despachos, comisiones y poderes, indicaciones sobre como dirigirse a distintas autoridades (el papa, obispos y arzobispos, universidades, gobernadores, corregidores) y como redactar los sobrescritos, instrucciones para interrogatorios, para la inspección de bibliotecas y para confiscación de bienes, y ejemplos de distintos tipos de provisiones.

Querría acabar simplemente llamando la atención sobre el interés del estudio de los formularios para conocer el funcionamiento de las escribanías de la Inquisición, pero sobretodo como manera de entender los intereses y preocupaciones protocolarias de la Inquisición misma. Por ejemplo, parece lógico suponer que la necesidad de dichas compilaciones se hizo manifiesta por la amplitud creciente del número de personas empleadas por la administración del Santo Oficio en la Edad Moderna. La larga lista de cargos que se deduce de las distintas fórmulas de nombramientos revela un cuerpo de funcionarios complejo y estratificado, en el cual es posible que se produjeran fricciones y conflictos de interés; es posible que un estudio de las características de dichos nombramientos pueda contribuir a un mejor conocimiento de las tareas de cada uno de dichos cargos y su relación entre ellos. Por otra parte, el control de la ortodoxia de la que se encargaban los sujetos de la Inquisición exigía que las fórmulas utilizadas en las distintas acciones a ejecutar (inspecciones, interrogatorios etc) fueran ajustadas a los principios y normas rectores. Seguir los modelos copiados en los formularios permitía no desviarse de dichas normas; a su vez, esos modelos nos permiten ahora darnos cuenta de la aplicación práctica de la legislación general. La comparación entre formularios de distintas épocas, aun cuando se trate de copias, puede informarnos de ciertas evoluciones: fórmulas que puedan aparecer o desaparecer a lo largo del tiempo, diferencias y similitudes entre los corpus de fórmulas de distintas secretarías. A los dos volúmenes mencionados podrían añadirse al menos otros cuatro formularios manuscritos: dos en el Archivo Histórico Nacional (AHN, Inquisición, libro 1314 y AHN, Inquisición, legajo 2138, exp. 9) y dos en la Biblioteca Nacional de España (BNE, Mss/798, Modo de proceder del Consejo de la Inquisición y BNE, Mss/6210, Formulario y modo de proceder del Santo Oficio). Sería interesante ver qué lecciones puede ofrecer su confrontación.

Se transcribe a continuación el sumario del volumen, intentando respetar al máximo la forma de presentación en tres columnas. Para facilitar la lectura, se han desarrollado las abreviaturas y se ha añadido puntuación y acentuación. 


\section{/f1/ Tabla d'este libro formulario}

Posesión

Avisso d'ella a las Inquisiciones por su Ill $^{\text {ma }}$

Falta de Inquisidor general

El Consejo da aviso a su Magestad de su falta

Sede Vacante

Sede Vaccante

Muerte de Rey o

Reyna

Lutos

Honrras

Licençias de ausençias

Consejo de Inquisición

Fiscal del Consejo

Secretario de la

Corona de Castilla

Secretario de la

Corona de Aragón

Relator del Consejo

Alguacil mayor del

Consejo

Receptor del Consejo

Nunçio del Consejo

Portero del Consejo

Médico del Consejo

Alcayde en Corte

Jubilación
Posesión de Inquisidor general (como la toma)

folio $1 .^{\circ}$

Primer despacho que se hace en tomando la posesión avisando a las folio $2 .^{\circ}$ inquisiciones

Despacho que el Consejo hace y embia a los Inquisidores quando falta folio 3 Inquisidor general

Consulta que el Consejo hace a su Magestad quando falta Inquisidor folio 3 general que a de contener y que se a de pedir suplique al Papa para que conçeda al Inquisidor general que suçediere

Sobre proveer officios en sede vacante

folio 4 y 10

Forma de despacho por el Consejo ${ }^{/ 11 \mathrm{v} /}$ en sede vacante en quanto a pro- folio 5 visiones de officios, dispensaciones y ayudas de costa hasta 9

Muerte de Rey y Reyna, lo que en qualquier d'estos casos se a de haçer folio 11

Lutos que a los ministros del Consejo se dan

folio 12

Forma en que el Consejo va a las honrras y vuelve d'ellas

folio 12

folio 13 cio por el secretario del Consejo y el de la Cámara que por ambas partes puede yr

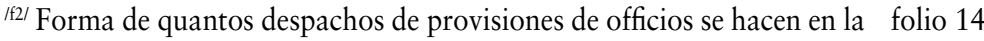
Inquisiçión mayores y menores, con todos sus requisitos desde el señor Inquisidor general a baxo

Al señor Inquisidor general nombra el Papa y en la facultad que le da folio 14 por la bula en que le nombra ya está dicho que suele haver limitación y mayor ampliación

Título de Consejero

Desde aquí comiença el Sr. Inquisidor general a yr proviyendo, y así se yrá discurriendo por todo, y asimismo los despachos del Rey, con que en muchas provisiones ${ }^{1 / 2 \mathrm{v} /}$ han de yr acompañados los del Inquisidor general

Título de fiscal del Consejo de Inquisición

folio 16

Título de secretario en la Corona de Castilla

folio 18

Título de secretario en la Corona de Aragón

folio 19

Título de relator del Consejo

folio 20

Inquisiciones que están señaladas a cada relator

folio 21

Título de Alguaçil mayor del Consejo

folio 22

Título de Receptor del Consejo

folio 23

Título de Nunçio del Consejo

folio 25

Título de Portero del Consejo

Título de médico del Consejo y que obligación tiene

folio 26

folio 27

Nombramiento de alcayde en esta corte

folio 28

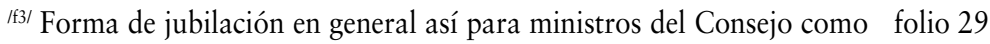
para los demás de las Inquisiçiones 


\section{/f1/ Tabla d'este libro formulario}

Tasador del Consejo

Calificador del

Consejo

Agente de Roma

Comissario de Corte

Secretario del Rey

Receptor de una

Inquisición

Inquisidor de Siçilia

Nunçio

Consultor ordinario

Alcayde de una

Inquisición

Cláusulas en cédulas

de salario

Cirujano

Notario de secerestos

Refrendata de títulos

Juez de bienes

Abogado del fisco

Médico

Notario del juzgado

Alguaçil

Inquisidor

Fiscal

Contador
Nombramiento del Consejo para tassador de pleitos

folio 30

Como es admitido un calificador en el Consejo de Inquisición

Título de agente de la Inquisición de España en Roma

Título de Comissario de corte

Título de secretario del Rey en lo que toca al Consejo de Inquisición

Despacho de receptor de las Inquisiciones

folio 31

folio 32

folio 33

folio 30

folio 40

folio 34

Despacho que a de llevar un Inquisidor que va a Siçilia

folio 44

dor general han de llevar para ser admit[id]os al exerçiçio de sus offiçios

Título de Nunçio de una Inquisiçión

folio 46

digo 45

folio 46

folio 47

Titulo de Alcayde de las Inquisiciones de Castilla y Aragón

folio 49

Palabras distinctas que en los títulos y cédulas de salario se ponen en los officios de Castilla y Aragón como pareçe en los libros

/f4/ Título de Cirujano de una Inquisiçión

folio 49

Título de Notario de secrestos de una Inquisiçión

folio 50

Como señala el Inquisidor general y refrenda el secretario del Rey los folio 51 títulos de ministros de Inquisición que el Rey firma para Siçilia

y lo que se hace en quanto a esto en la Corona de Aragón

Poder de Juez de bienes

folio 52

Título de Abogado del fisco

/f4v/ Título de Médico de una Inquisiçión

folio 54

folio 56

Título de Notario del juzgado

Título de Alguaçil de una Inquisiçión

folio 57

folio 58

Título de Inquisidor

folio 59

Título de Fiscal

folio 61

folio 63

folio 67

folio 69

Poder de visitador de un Inquisidor

y recados que a de llevar

${ }^{145 /}$ Comissión a un inquisidor para tomar las quentas en una Inquisición folio 86

Despacho que a de llevar el Inquisidor y ministro de la Inquisición que folio 89 han de andar en la armada

Edicto de graçia a los christianos renegados

folio 96

Comissión para executar la resoluçión de una visita

folio 97

Título de procurador del fisco de una Inquisición

folio 100

Librança del Inquisidor general en el receptor del Consejo y de quantas folio 101 maneras puede yr

Habilitaçión en lo arbitrario a ${ }^{/ 55 v /}$ fulano hija o hijo de condenado

folio 102

Comutaçión a un condenado a galeras

folio 103

Para que dando un sclavo un condenado a galeras sirva por él

folio 104 


\section{/f1/ Tabla d'este libro formulario}

Revocaçión de poder de Inquisidor y de otro qualquier ministro

folio 105

Título de ayudante del secreto

folio 106

Comutaçión en penitençias spirituales

folio 107

ff6/ Poder que el cardenal de Toledo a de otorgar a su vicario para asistir folio 108 a los negocios de fee

Liçencia a un condenado para que salga de estos reynos folio 110

Para que uno çelebre que estaba suspenso de deçir misa folio 111

Título de Assessor folio 112

Título de Alcayde de la cárçel de la Penitençia folio 113

Poder de Contador de las tres Inquisiciones de la Corona de Aragón folio 114

1f6r/ Título de Nuncio y portero todo junto folio 117

Raçón de la causa por qué en la Corona de Aragón se pone el Rey en folio 118

las çédulas al lado

Título de Notario de corte

Cédula de salario en la forma que se solía despachar quando en el título folio 120

no yva inclusa la cláusula del salario como ahora va

Sobreescriptos a las Inquisiciones de Castilla $\quad$ folio 121

Sobreescriptos a las de Aragón folio 123

Los del Consejo como escriven en particular a las Inquisiciones folio 124

1f7/ Como escrive el contador al agente en Romar folio 124

Advertencia en materia de los portes quando llevan esta palabra «fisco» folio 124

o sin ella

Comissión a uno de los srs. del Consejo para tomar las quentas folio 125

Comissión al contador para que execute un alcançe en un receptor folio 126

Comissión del Consejo a un personaje particular para que averigüe folio 127 unos delictos cometidos por un comissario del Santo Officio y compulse qualesquier proçesos criminales

Procuración general para que los comissarios de qualesquier puertos folio 129 embien $^{/ \mathrm{f} 7 \mathrm{v} /}$ cerradas y selladas unas balas de libros

o tapiçerías

Cédula de paso a un ministro que a de pasar por los puertos de los folio 131

Reynos de Aragón

Poder de Procurador fiscal en causas çiviles del Consejo de Inquisición folio 132

Forma en que se han de otorgar las scripturas por los fiadores que los folio 134 que han de ser receptores de las Inquisiçiones dan al Santo Officio

Que no se tomen por eltanto ${ }^{6}$ mantenimientos que estuvieren compra- fol.

dos por otros que no sean de la Inquisición ni ministros d'ella

188/ Despacho que se haçe quando uno hace de raçión de su officio folio 134

Forma del despacho cuando se ha de haçer cathálogo y expurgatorio folio 134 de libros

Primer consulta

página $2 .^{\mathrm{a}}$

Al embaxador sobre lo dicho

página $2 .^{\mathrm{a}}$

folio 138

6 Probablemente, error de copia por «sentado». 


\section{/11/ Tabla d'este libro formulario}

Instrucçión al embaxador de lo que a de pedir al Papa de parte de su folio 141 Magestad acerca del expurgatorio

Título de familiar en todos los reynos de España al Conde de Benavente folio 159 año de 1624

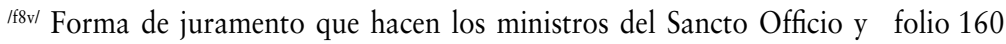
así mutatis mutandis le deven hacer aquí en el Consejo para lo qual ay muchas raçones

Forma de leerse el Anathema

folio 162

Ase de juntar este Interrogatorio de presos y cárceles

folio 163

interrogatorio con el del folio 69

Forma de edicto que por mandado del Consejo se hace en nombre de la folio 165 Inquisición de Toledo para prohibir un libro en la corte

Título de consiliario del Concejo ${ }^{\text {/f9/ }}$ de Inquisición a un sr. del Concejo Real folio 166 Salarios que se dan y quanto a los ministros de las Inquisiciones folio 167

Salarios a los ministros del Consejo folio 170

Poder de Colector de frutos de las canonjías y prebendas folio 171

Forma en que por este Consejo escribe su magestad a su santidad folio 174 Forma en que por este Consejo escribe su magestad a los cardenales de Roma folio 174 Forma en que se escribe al arçobispo de Toledo folio 175 Forma en que se escribe a todos los prelados de Castilla folio 175

${ }^{\wedge f 9 v /}$ Forma en que por el Consejo de Inquisición se escribe a los grandes folio 175 por su magestad

página $2 .^{\text {a }}$

Forma en que por su magestad se escribe a las universidades de Castilla folio 177 por este Consejo

Forma en que su magestad escribe por este Consejo a todos los corregi- folio 178 dores fuera de los puertos

y a los de los puertos

Forma de como se ponen los sobreescritos al Papa y a los cardenales

folio 179

Forma de como se ponen los sobreescritos a los grandes

folio 179

Como se hace esto en la Corona de Aragón

folio 180

folio 180

Sobrescritos a los obispos de Castila y Aragón

folio 181

/f10/ Receptoría por el Consejo como se hace

folio 181

Receptoría como se hace por Don Philipe

folio 183

Emplaçamiento compulsorio

folio 185

Testimonio de como el Consejo de Inquisiçión manda imprimir como folio 189 real sin intervençión de otro ninguno

Interrogatorio de defensas para quando el Inquisidor de Madrid ful- folio 190 mina en esta corte aguna causa conforme a stilo de la Inquisición de Toledo y del Sancto Officio

/f10v/ Título de Agente general del Consejo

folio 209

Título de Alcayde del Consejo en esta corte

folio 208

Forma en que se scrive al gobernador de Milán y a otros virreyes ${ }^{7}$

folio 210

7 En origen, entrada en el margen inferior de la hoja 9 vuelta. 


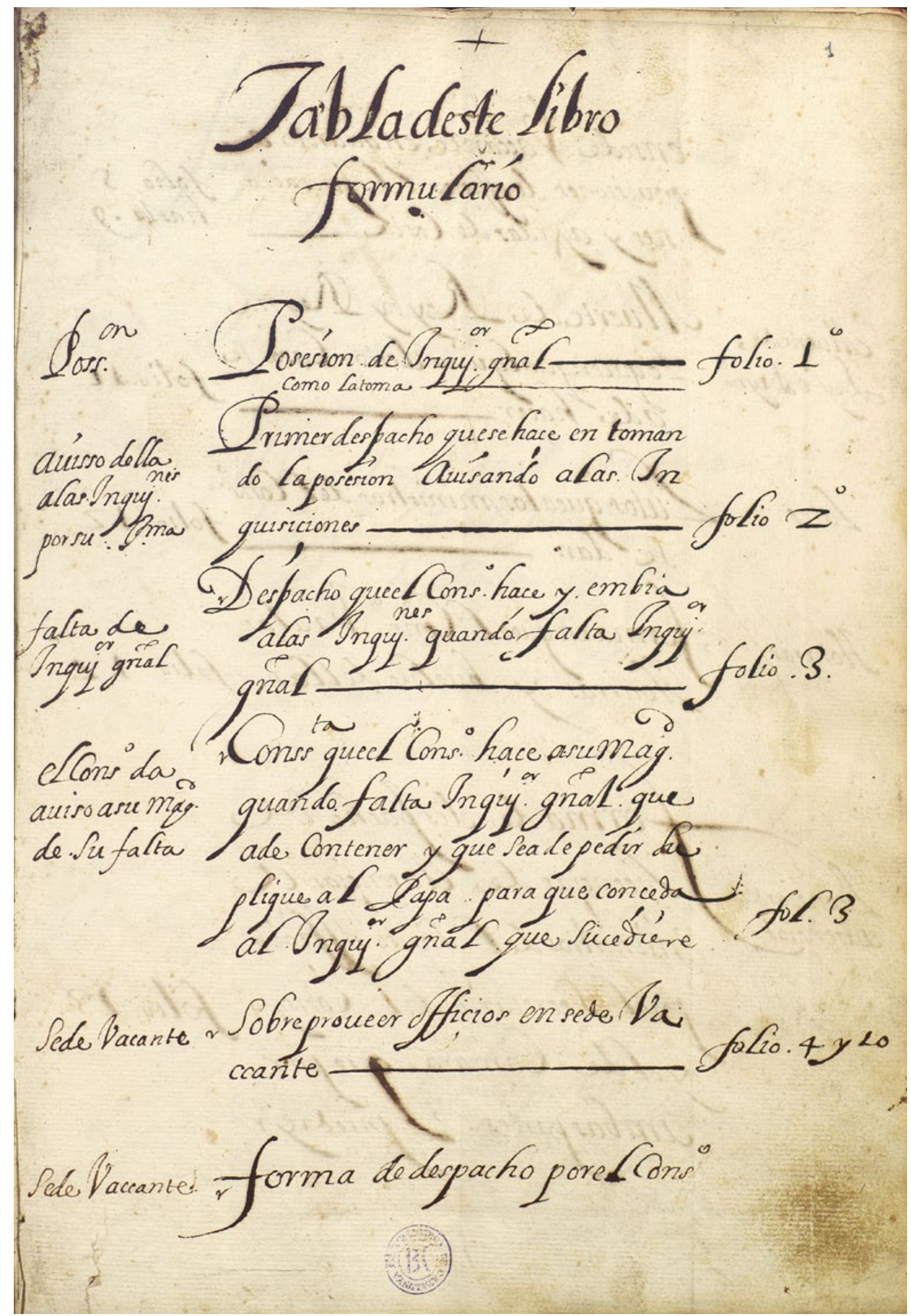

Figura 3. BC, ms. 2168, f. 1. Tabla deste Formulario. 


\section{LISTA DE REFERENCIAS}

Avilés, M., Martínez Millán J. \& Pinto Crespo, V. (1978). El archivo del Consejo de la Inquisición: aportaciones para una historia de los archivos inquisitoriales. Revista de Archivos, Bibliotecas y Museos, 81(8), 459-518.

Cabezas Fontanilla, S. (2002). La carta acordada: nacimiento y consolidación de un documento inquisitorial. Hidalguía, 294, 713-726.

Cabezas Fontanilla, S. (2005). Las secretarías del Consejo de la Inquisición y su sistema de producción documental (siglos XV-XVII). Boletín de la Sociedad Española de Ciencias y Técnicas Historiográficas, 3, 211-238.

Givanel de Pujol, D. (1969). La colección teatral de don Arturo Sedó, vista por su bibliotecaria. San Jorge, 73, 25-33. Recuperado de http://media.diba.cat/ diba/fitxers/arxiu/Revista-San-Jorge/San-Jorge-1969-73.pdf.

Martínez Millán, J. (2017). Los problemas de la Inquisición en tiempos de Carlos II. Libros de la Corte.es, 6, 11-38. Recuperado de https://revistas.uam.es/librosdelacorte/article/view/8722, https://doi.org/10.15366/ldc2017.9.m6.001

Montaner, J. (1951). La colección teatral de don Arturo Sedó. Barcelona: Seix i Barral.

Pérez Fernández-Turégano, C. (2015). El archivo de la Secretaría de Aragón del Consejo de la Inquisición: Domingo de la Cantolla Miera y su labor recopiladora en el tránsito del XVII al XVIII. Revista de la Inquisición (intolerancia y derechos humanos), 19, 41-74. 